Cooper, K. E. \& Ramadan, F. M. (1955). J. gen. Microbiol. 12, 180-190

\title{
Studies in the Differentiation between Human and Animal Pollution by means of Faecal Streptococci
}

\author{
BY K. E. COOPER AND F. M. RAMADAN \\ Department of Preventive Medicine, University of Bristol
}

With a Note on the Standardization of the Janus Green Milk Test

SUMMARY: The isolation of faecal streptococci from the excreta of man, cattle and sheep was investigated. The methods compared were $(a)$ heat, $(b)$ tetrathionate, $(c)$ tellurite, $(d)$ thallium salts. The tellurite method proved highly efficient, isolating $97 \%$ of strains from human, cow and sheep faeces. A survey of the properties of strains isolated was made. Differential tests based on $(a)$ heat resistance and (b) reducing properties were devised; these divided the streptococci isolated by the tellurite method into groups, some of which were characteristic of the source. The information available seems capable of distinguishing many strains obtained from man from those derived from cows or sheep, and it is suggested it may be of use in tracing sources of pollution in water, milk and other foodstuffs.

No satisfactory method exists at present for distinguishing faecal pollution by human sources from that by other animal sources. The chief organism used in proving faecal pollution, namely Escherichia coli type I, may arise from either source (see Rep. Minist. Hlth, Lond. 1940). Faecal streptococci have also been advocated as confirmatory evidence of pollution, but the significance of different types has been little investigated. The nature of the types isolated from faecal material depends to some extent on the method of isolation. The strains isolated by the two methods proposed in the Ministry report, namely the heating method and the tellurite method, are often different. Other methods of isolation are also possible. Cooper, Baker, Elliot \& Wood (1942) reported the isolation by tetrathionate media, and Cooper \& Linton (1947) showed the resistance of these organisms to thallium acetate. The use of sodium azide was investigated by Allen, Pierce \& Smith (1953).

The present paper describes the results of experiments which compared these various methods (except the use of azide), and a more extended investigation of the streptococci obtained from human, cow and sheep faeces by the tellurite method. As a result it appears that a high percentage of strains have properties which enable their source to be determined with considerable certainty. The faecal streptococci, therefore, in contrast to Escherichia coli may prove of value in tracing pollutions in water, milk and other foodstuffs.

The isolation of streptococci by tetrathionate broth and by heat $\left(60^{\circ}\right.$ for $\frac{1}{2} \mathrm{hr}$.) was compared by Cooper, Baker, Elliot \& Wood (1942), and though equally successful from human faeces, showed that heat destroyed many strains in cattle excreta. That investigation, and a further one in 1950, revealed that three-quarters of the streptococcal strains isolated from cattle and sheep produced green-yellow discoloration on heated blood agar. Less than one- 
quarter of the human strains did this; for the media used see Cooper, MayrHarting \& McLachlan (1950). However, variability of the results on repeated subculture and with changes in the media led us in this investigation to study reducing properties instead of the production of peroxides.

\section{SURVEY OF ISOLATION METHODS}

Thirty specimens of faeces from human, cow and sheep sources were concentrated in three different media, namely:

(a) Tetrathionate broth as used for the isolation of Salmonella paratyphi $\mathbf{B}$ from faeces (Cooper, Wood, Elliot, Caswell \& Small, 1942).

(b) Potassium tellurite medium: a modification of the medium of Harold (1936) for isolation of streptococci from water was used; potassium tellurite, final concentration $1 / 5000$ in $0.5 \%$ lactose, $0.5 \%$ peptone water buffered at pH 7.6 with $0.5 \%$ potassium phosphate.

(c) Thallium acetate medium which contained $0.5 \%$ peptone, $0.5 \%$ lactose, $0.5 \%$ anhydrous dipotassium phosphate and thallium acetate to make final concentration 1/2000 (Cooper \& Linton, 1947).

Method. A loopful of excreta was emulsified in $10 \mathrm{ml}$. sterile water; filtered through four layers of muslin, the filtrate mixed and with a Pasteur pipette 10 drops inoculated into tubes of each of the three media. Plate cultures were made after $24 \mathrm{hr}$. on to MacConkey agar (0.5\% sodium taurocholate) and incubated for a further 24 hr. Streptococcal colonies were picked and subcultured on $10 \%$ heated blood agar until pure. A well-defined colony was distributed in Bactopeptone broth and then incubated at $37^{\circ}$ for $16 \mathrm{hr}$. The resulting growth was examined microscopically and subjected to a series of biochemical tests to study the following properties:

Haemolysis. Shattock's modification (1949) of Brown's technique.

Gelatin liquefication. Stab cultures observed over 14 days at room temperature.

Action in litmus milk at $37^{\circ}$. The term 'strong litmus reduction' was applied to cases where the dye was totally reduced in the depths of the tube in $24 \mathrm{hr}$. with or without colour change at the surface. The medium ( $5 \mathrm{ml}$.) was in screwcap bottles ( 1 oz. McCartney), incubated with the stopper tight and not shaken.

Survival at $60^{\circ}$ for $30 \mathrm{~min}$. A sample $(0.5 \mathrm{ml}$.) of culture in Bactopeptone broth was transferred into a Widal tube $(65 \times 9 \mathrm{~mm}$.) and placed in a waterbath at $60^{\circ}$ with the level of culture well below the water and heated for $30 \mathrm{~min}$. The tubes were then transferred to another water-bath at $37^{\circ}$ and kept for $2 \mathrm{hr}$. Subcultures were then made on $10 \%$ heated blood agar and plates incubated for $48 \mathrm{hr}$. and examined for growth.

Growth at $\mathrm{pH}$ 9·6. Method of Shattock \& Hirsch (1947).

Inhibition by $6.5 \%$ sodium chloride. Method of Abd-el-Malek \& Gibson (1948).

Inhibition by $0 \cdot 1 \%$ methylene blue. A loopful of culture was inoculated in $5 \mathrm{ml}$. sterile skimmed milk containing $0.1 \%$ methylene blue and incubated in a water-bath at $37^{\circ}$. The results were read after $24 \mathrm{hr}$. 
Growth on $40 \%$ ox bile medium. Abd-el-Malek \& Gibson (1948).

Starch hydrolysis. Poured plate cultures made by using $1 \mathrm{ml}$. culture and melted $0.2 \%$ starch agar cooled to $45^{\circ}$. Hydrolysis tested with iodine solution after 5 days at $37^{\circ}$.

Sodium hippurate hydrolysis. Ayers \& Rupp (1922).

Sugar fermentation reactions were observed in peptone water to which was added a sterile solution of $0.5 \%$ sucrose, lactose, raffinose, inulin, mannitol, or $1 \%$ glycerol, and phenol red.

\section{RESULTS}

\section{Isolation methods}

By using the three selective media 195 strains of streptococci were isolated from the ninety specimens of faeces. The relative number of strains recovered by each medium in accordance with its value as a method of isolation is shown in Table 1. Tetrathionate broth, though often successful with human faeces, failed rather significantly in concentrating streptococci from sheep and bovine faeces. Proteus vulgaris, micrococci and yeasts were usually prevalent.

\section{Table 1. Incidence of streptococci isolated by three different methods}

\begin{tabular}{|c|c|c|c|c|c|c|c|c|}
\hline & & \multicolumn{5}{|c|}{ Method of isolation } & & \\
\hline & & \multicolumn{2}{|c|}{ Tetrathionate } & \multicolumn{2}{|c|}{ Tellurite } & \multicolumn{2}{|c|}{ Thallium acetate } & \multirow{3}{*}{$\begin{array}{c}\text { Total strains } \\
\text { isolated } \\
72\end{array}$} \\
\hline \multicolumn{2}{|c|}{ Faeces } & $\begin{array}{l}\text { No. of } \\
\text { strains }\end{array}$ & $\begin{array}{c}\% \text { of } \\
\text { success }\end{array}$ & $\begin{array}{l}\text { No. of } \\
\text { strains }\end{array}$ & $\begin{array}{c}\% \text { of } \\
\text { success }\end{array}$ & $\begin{array}{l}\text { No. of } \\
\text { strains }\end{array}$ & $\begin{array}{c}\% \text { of } \\
\text { success }\end{array}$ & \\
\hline Human & 30 & 18 & 60 & $\mathbf{3 0}$ & 100 & $\mathbf{2 4}$ & 80 & \\
\hline Bovine & 30 & 1 & $\mathbf{3}$ & 28 & 93 & 28 & 93 & 57 \\
\hline Sheep & $\mathbf{3 0}$ & $\boldsymbol{7}$ & 23 & 29 & 96 & 30 & 100 & 66 \\
\hline Total & 90 & 26 & 29 & 87 & $96 \cdot 7$ & 82 & $91 \cdot 1$ & 195 \\
\hline
\end{tabular}

The strains isolated by each method usually differ in properties and have therefore been regarded as distinct, though originating from the same specimen.

Potassium tellurite medium proved to be highly selective in concentrating streptococci from human and animal faeces ( $97 \%$ of specimens). The advantage of a concentration of $1 / 5000$ is that it helps to diminish Proteus vulgaris and fungi which are often predominant in animal faeces. Fleming (1932) discovered that some proteus strains resist $1: 8000$ potassium tellurite and that 1:5000 did not affect faecal streptococci. Additional experiments with solid media revealed that faecal streptococci from man, cow and sheep multiplied on nutrient agar or $(\mathbf{1 0} \%)$ heated blood agar containing $\mathbf{0 . 2} \%$ potassium tellurite.

Thallium acetate medium may be considered equal to tellurite medium in securing heavy pure growth of streptococci from animal faeces but it failed in a considerable number of cases with human faeces. 


\section{Strains isolated}

By using the three methods of isolation it was possible to obtain at least one streptococcus strain from every specimen of faeces. Usually strains with different characters were recovered from the same specimen when treated with different methods. Strains which showed all the classical characteristics of named species have been so designated. In an endeavour to classify the other streptococci into convenient groups the first eight characters presented in Table 2 were taken as the basis for differentiation. According to this method, $40 \%$ of human-derived streptococci were grouped as Streptococcus faecalis, a specific name given by Andrewes \& Horder (1906) and firmly established by Dible (1921) and Sherman (1938). Typical $S$. faecalis, as described in Table 2, did not exist among streptococei derived from cow and sheep faeces. $S$. durans was also only recovered from human faeces and represented $4 \%$ of human strains. S. faecalis var. liquefaciens and $S$. faecalis var. zymogenes accounted for about $29 \%$ of the human-derived streptococci. The liquefaciens variety represented a group of $14 \%$ of bovine and $18 \%$ of sheep strains. The zymogenes variety was not encountered among the bovine organisms but formed $6 \%$ of streptococci from sheep. Many investigators have recovered the liquefaciens and zymogenes variants from human faeces, milk, ice-cream, dried milk and cheese, but there seems no evidence from the available literature that they have been noticed before in bovine or sheep faeces.

Human, bovine and sheep faeces share in common several groups of streptococci which differ from the typical Streptococcus faecalis in one or more essential criteria and usually other secondary ones. Since the object of the present work is the subdivision of streptococci from various sources into groups convenient for differential purposes, the name 'Atypical faecalis' designated I, II, III, IV and V was applied to those strains which differed from the typical faecalis in one, two or three standard characters. These undoubtedly would include most of the unclassified and the so-called $S$. faecalis 'variants' and 'enterococcus-like' organisms recorded by several investigators.

Only one strain of Streptococcus bovis was encountered among the humanderived collection. Unlike the other $S$. bovis strains this one failed to ferment starch. Orla-Jensen (1942) observed that human strains of $S$. bovis did not hydrolyse starch. $S$. bovis represented $28 \%$ of streptococci recovered from cow dung; none was found in sheep dung. The presence of $S$. bovis in small numbers in the human intestine had been recognized by many investigators; Sharpe (1948) encountered thirty-seven $S$. bovis strains out of 340 streptococcal strains recovered from the faeces of human infants. This high incidence may be attributed to the common presence of this organism in cow's milk which may be incompletely sterilized for infant feeding. The recovery of $S$. bovis in only $28 \%$ of bovine-derived strains is a result different from that of Ayers \& Mudge (1923) who considered $S$. bovis as the predominating streptococcus in bovine intestine. This difference in findings may be due to the methods of isolation used or to the different criteria for identification. None 


\begin{tabular}{|c|c|c|c|c|c|c|c|c|c|c|c|c|c|c|c|}
\hline I07!qIOS \& & $\dot{4}$ & $\dot{4}$ & 1 & $1<$ & $\dot{4}$ & 1 & $\dot{4}$ & $1+$ & $\stackrel{\infty}{+1}$ & 1 & $\begin{array}{l}\underbrace{}_{N} \\
+1\end{array}$ & $\dot{4}$ & $\begin{array}{l}2 \\
+1\end{array}$ & 1 & 1 \\
\hline โоләอКโฏ < & $\dot{4}$ & $\dot{4}$ & 1 & $1<$ & 1 & 1 & $\dot{4}$ & $i+$ & +1 & 1 & $\begin{array}{l}\stackrel{9}{*} \\
+1\end{array}$ & $\dot{4}$ & 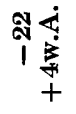 & 1 & 1 \\
\hline ụ̣nư I & 1 & 1 & 1 & 81 & 1 & $\dot{4}$ & 1 & 1 & 1 & 1 & 1 & & 1 & 1 & 1 \\
\hline
\end{tabular}

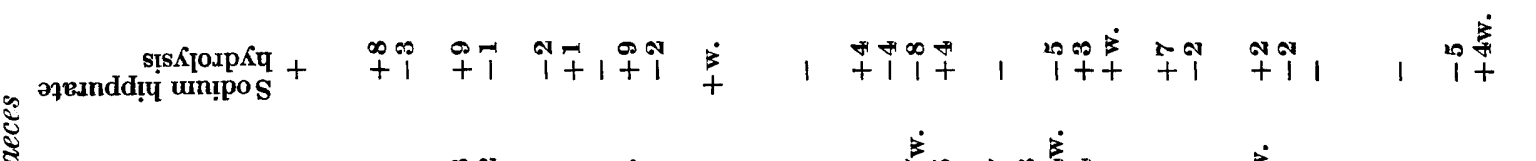

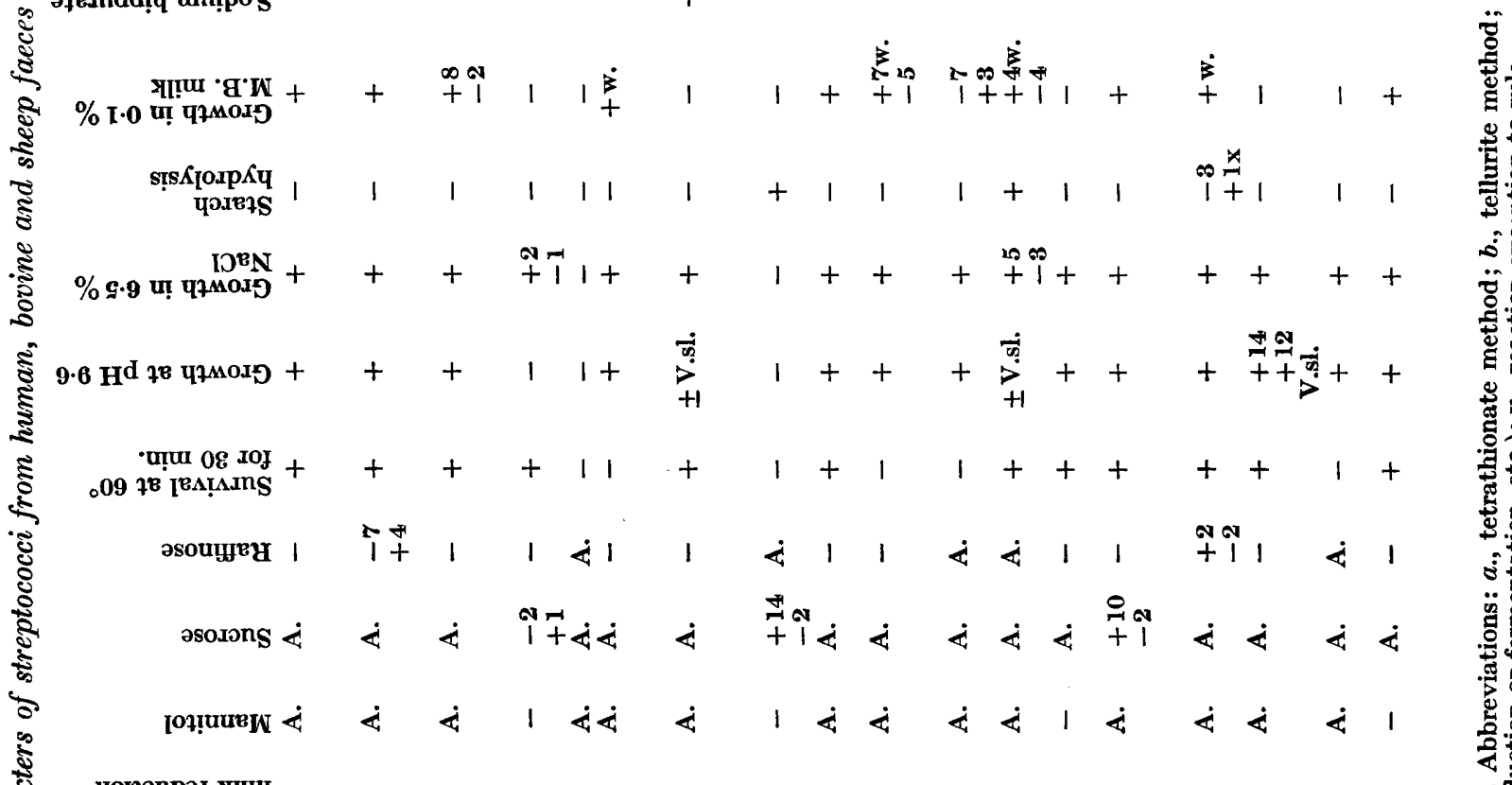

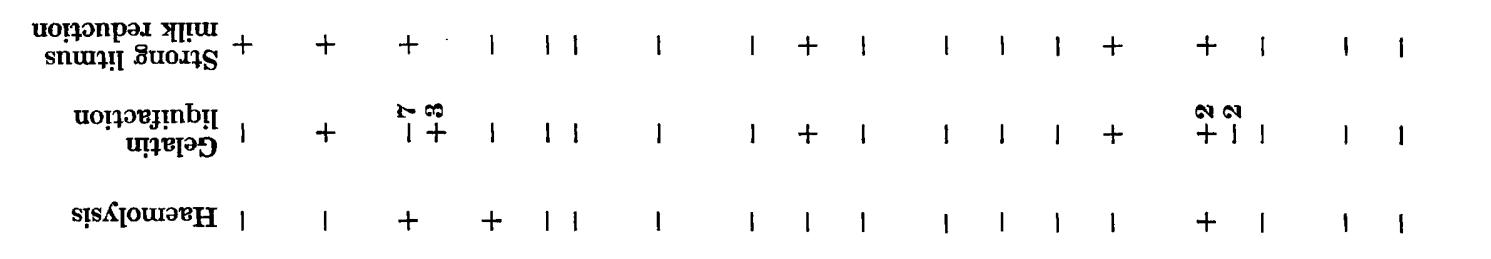

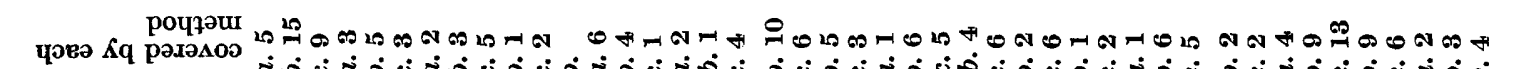
-al suremp jo on ง

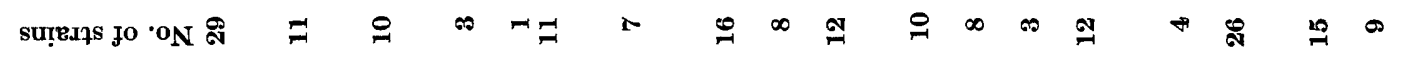
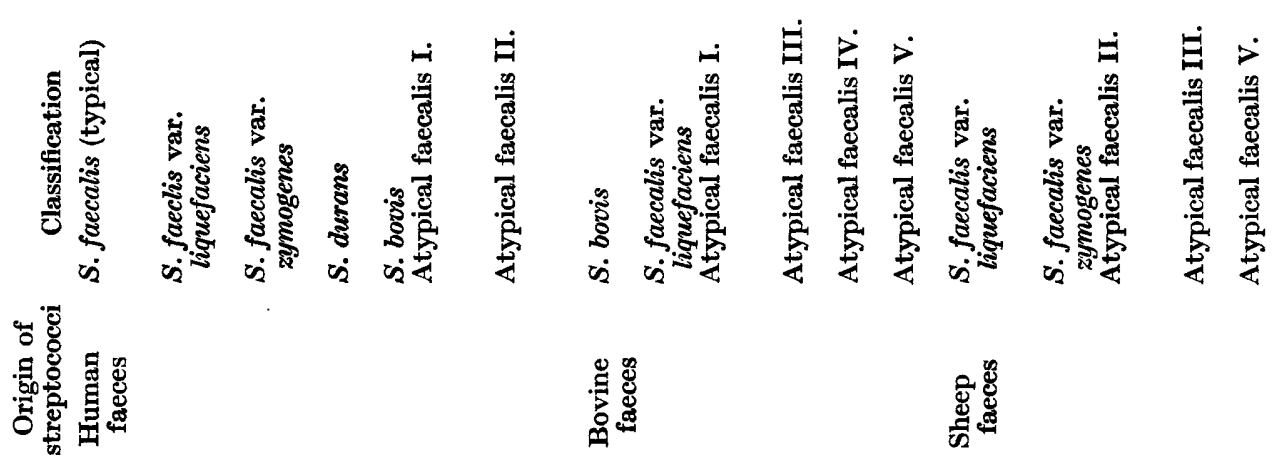
of our $S$. bovis strains was capable of surviving a temperature of $60^{\circ}$ for $30 \mathrm{~min}$. This is contrary to Sherman's findings (1937) and agrees with observations made by Shattock \& Mattick (1943). The discrepancy may be due to differing amounts of peroxide formed in varying media, as a lethal factor additional to the temperature.

\section{SURVEY OF DIFFERENTIAL TESTS FOR INDICATING SOURCE}

The tests used to distinguish species within this group have increased in number and variety in recent years, and this has resulted in a multiplicity of recognizable types. Which of these types are worthy of being called species, or indeed, which of the tests employed should be regarded as diagnostic and which as only showing minor variants is still disputed. We are not here primarily concerned with classification but with the value of some of these tests as an indication of the sources of the strains concerned.

\section{Choice of method of isolation}

The method of isolation itself determines some of the characteristics of the strains isolated. The use of $1 / 5000$ potassium tellurite followed by subculture to MacConkey agar ( $0.5 \%$ sodium taurocholate) isolated a high proportion $(97 \%)$ of the bile-resistant enterococci from faeces of man, cow and sheep. This work requires extension to other sources of pollution such as birds, pigs, dogs, cats, rabbits, rats, etc.; nevertheless, the strains thus isolated probably represent the predominant organisms likely to gain access to water or milk supplies. Isolations by this method were therefore made from $\mathbf{3 5 0}$ specimens of faeces (130 human, 110 cow, 110 sheep). Bactopeptone broth cultures $\left(16 \mathrm{hr} ., 37^{\circ}\right)$ of the purified strains isolated were prepared for examination by different tests ( 343 strains).

\section{Choice of differential tests}

Earlier work had suggested the value of heat-resistance tests and of tests for oxidizing or reducing ability. The difference between human and animal strains was of a quantitative nature and best demonstrated on freshly isolated strains. With a view to avoiding, if possible, prolonged quantitative measurements it was decided to utilize a dye which indicated different degrees of reduction, and Janus Green in milk was therefore compared with the previously used litmus milk. The heat test was made a little more severe $\left(63^{\circ}\right.$ for $30 \mathrm{~min}$.), and the recovery of strains was tested not only in a rich medium $(10 \%$ heated blood agar), but also on McLeod's tellurite medium (Anderson, Happold, McLeod \& Thompson, 1931).

Heat-resistance tests. A sample $(0.5 \mathrm{ml}$.) of culture was transferred into a Widal tube $\left(65 \times 9 \mathrm{~mm}\right.$.); the tube placed in a water-bath at $63^{\circ}$ with the level of the culture well below the water and heated for $30 \mathrm{~min}$. The tube was then transferred to another water-bath at $37^{\circ}$ and kept for $2 \mathrm{hr}$. With a $4 \mathrm{~mm}$. diameter loop one loopful was subcultured: (i) to a (10\%) heated blood agar 
and the plate incubated for $48 \mathrm{hr}$. after which it was examined for growth; (ii) to McLeod's tellurite medium and the plate incubated at $37^{\circ}$ for $48 \mathrm{hr}$. and examined for growth.

Janus Green milk test. Janus green B (dimethylsafranin azodimethylaniline; a Gurr preparation; batch no. 1041, see p. 189) was dissolved in sterile glassdistilled water to form a $1 \%$ solution. The dye solution was heated in a waterbath at $80-100^{\circ}$ for $15 \mathrm{~min}$. and left to cool. It was then added to sterile separated milk to bring the final concentration to $1 / 10,000$ and the medium distributed in $5 \mathrm{ml}$. amounts in screw-capped bottles. One loopful (4 $\mathrm{mm}$. diameter) of inoculum from the broth culture was transferred to a screw-capped bottle of medium and incubated along with a non-inoculated bottle of medium as control in a water-bath at $37^{\circ}$. Readings were made after $16 \mathrm{hr}$. to record the rate of reduction of the dye in the milk culture.

Litmus milk reduction test. One loopful $(4 \mathrm{~mm}$. diameter) of broth culture was put in $1 \%$ litmus milk and the bottle incubated in a water-bath at $37^{\circ}$ for $16 \mathrm{hr}$. after which the changes and rate of reduction of litmus in the milk culture were recorded. These technical procedures were conducted on adequate numbers of human, cow and sheep-derived strains in parallel, so that the conditions under which these strains were tested may be considered comparable.

\section{RESULTS}

The tellurite method isolated streptococci from $127(97 \cdot 6 \%)$ of 130 samples of human faeces; from 106 of 110 samples $(96.3 \%)$ of cow faeces and from 110 of $110(100 \%)$ samples of sheep faeces, which when examined by the above procedure revealed the findings stated in Table 3. It was found that when Janus Green B underwent reduction in a milk culture, a series of changes in colour occurred in the following order: blue $\rightarrow$ mauve $\rightarrow$ violet $\rightarrow$ dirty red $\rightarrow$ wine red (quinonoid) $\rightarrow$ rosy pink $\rightarrow$ pale pink $\rightarrow$ colourless. The Janus Green milk test was considered positive when the colour of the dye reached after $16 \mathrm{hr}$. at $37^{\circ}$ was the quinonoid red (semi-reduced form) or any shade following it towards the leucoform of the dye. The rosy pink colour, however, was that most often observed in positive Janus Green milk tests. On the other hand, a negative result was taken as indicated by any culture in which the colour lay between the blue and the dirty red shades. To avoid confusion between 'dirty red' and 'quinonoid red', the cultures were shaken before examination, thus allowing atmospheric oxygen to restore the violet shade to cultures which had not been reduced to the quinonoid red form.

The Janus Green milk test revealed $85 \%$ positive results among strains of human origin, and only $19 \cdot 4 \%$ among those of animal origin. The results obtained with the litmus milk test showed that $72.4 \%$ of human-derived strains and $46.2 \%$ of the animal-derived ones were capable of reducing the dye to the colourless form during the same period of incubation.

Janus Green has shown itself to be a better indicator than litmus of the relative degree of reduction of streptococcal milk cultures. Unlike litmus, Janus Green does not change colour so readily with $\mathrm{pH}$ changes of the medium 
which makes it a more suitable indicator for the present purpose of indicating degrees of reduction. In comparing the results of the two tests on the same strains under the same conditions, not only did the Janus Green test show superiority in detecting a higher percentage of strong-reducing strains among the human-derived cultures, but it also gave less than half the percentage of reducing strains among the animal-derived cultures than did the litmus test. About 50\% of cultures which did not reduce Janus Green within $16 \mathrm{hr}$. did so on incubation for a further $24 \mathrm{hr}$. This suggests that differences among excremental streptococci in their rate of Janus Green reduction are mainly due to differences in ability to reduce the dye rather than differences in their susceptibility to the antiseptic effect of the dye.

\section{Table 3. Incidence of positive and negative biochemical tests shoron by} streptococci of different origin

\begin{tabular}{|c|c|c|c|c|c|}
\hline Origin & $\begin{array}{c}\text { Total } \\
\text { no. of } \\
\text { strains }\end{array}$ & $\begin{array}{c}\text { Heat-resistance } \\
\text { test } \\
\left(63^{\circ}, 30 \mathrm{~min} .\right)\end{array}$ & $\begin{array}{c}\text { Heat and } \\
\text { tellurite } \\
\text { resistance test }\end{array}$ & $\begin{array}{l}\text { Janus Green } \\
\text { milk test }\end{array}$ & $\begin{array}{l}\text { Litmus } \\
\text { milk test }\end{array}$ \\
\hline Human & 127 & $\begin{array}{l}+115(90.5 \%) \\
-12(9.5 \%)\end{array}$ & $\begin{array}{l}+97(76.4 \%) \\
-30(23.6 \%)\end{array}$ & $\begin{array}{l}+108(85 \%) \\
-\quad 19(15 \%)\end{array}$ & $\begin{array}{l}+92(72 \cdot 4 \%) \\
-35(27 \cdot 6 \%)\end{array}$ \\
\hline Cow & 106 & $\begin{array}{l}+22(20.7 \%) \\
-84(79.3 \%)\end{array}$ & $\begin{array}{l}+\quad 0(0 \%) \\
-106(100 \%)\end{array}$ & $\begin{array}{l}+21(19.8 \%) \\
-85(80.2 \%)\end{array}$ & $\begin{array}{l}+44(41 \cdot 5 \%) \\
-62(58.5 \%)\end{array}$ \\
\hline Sheep & 110 & $\begin{array}{l}+35(31.8 \%) \\
-75(68.2 \%)\end{array}$ & $\begin{array}{l}+\quad 0(0 \%) \\
-110(100 \%)\end{array}$ & $\begin{array}{l}+21(19 \%) \\
-89(81 \%)\end{array}$ & $\begin{array}{l}+56(50 \cdot 9 \%) \\
-54(49 \cdot 1 \%)\end{array}$ \\
\hline
\end{tabular}

The heat-resistance test revealed that $90.5 \%$ of the human and $26.3 \%$ of the animal strains were thermoduric. Heating at $63^{\circ}$ was the temperature of choice. It gave a better differential test than that at $60^{\circ}$. It may be worth recording that some human strains were found to resist heating at $63^{\circ}$ for $1 \mathrm{hr}$. and some for $90 \mathrm{~min}$.

Faecal streptococci, when subjected to the heat-test fell into three categories: $(a)$ strains killed by heat; $(b)$ strains which survived the heat test but were subsequently not able to survive on the inhibitory medium; $(c)$ strains which survived the two processes. Most of the heat-resistant strains from human faeces (84.3\%) qualified as category $(c)$, i.e. survived both processes; none of the animal strains which survived the heat test belonged to this category.

The inhibition of growth of heat-treated cells on a $0.04 \%$ potassium tellurite medium seems to be due to a weakness in the resistance of these cells acquired as a result of heat treatment, rather than to a bactericidal action of potassium tellurite. These same strains when unheated produced profuse black growth on McLeod's medium. That $0.04 \%$ potassium tellurite is an important factor in the disinfection process was shown by the observation that a medium containing $0.02 \%$ of that chemical generally supported the growth of heat-treated cells.

\section{Significance of differential tests}

When the strains examined are classified according to the two heat-resistance tests and the Janus Green reduction test into the six possible groups (Table 4), then the source of strains falling into some of these groups seems to be indicated 
clearly. Groups I and II were derived entirely from human sources; other animal sources accounted for $98.5 \%$ of group III and $91 \%$ of group IV. Strains with the characters of groups V and VI were less characteristic of a particular source.

Table 4. Biochemical grouping of faecal streptococci

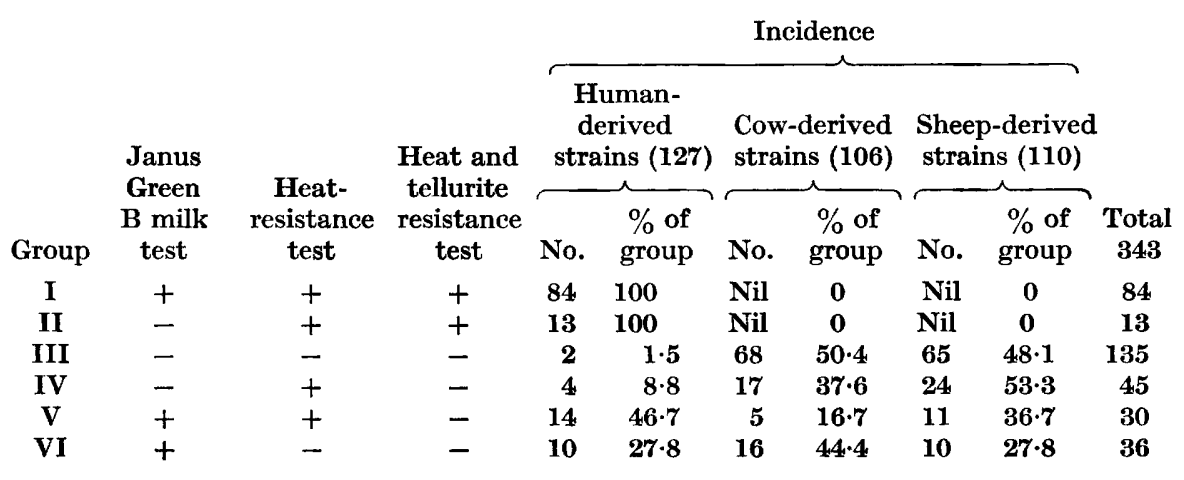

\section{Conclusions}

Whether strains with these characteristics will be as diagnostic of their source when a wider field is surveyed, remains to be seen. Our results suggest that with carefully devised tests it should be possible to distinguish human pollution from animal pollution by means of the faecal streptococci. The application of such tests after the tellurite method of isolation should be further investigated, and also compared with results by other methods of isolation such as the glucose + yeast-extract + sodium azide method advocated by Allen et al. (1953). The final identification of a strain by the use of most of the tests used in Table 2 will sometimes give more conclusive results. The characterization of a strain as typical Streptococcus faecalis seems to indicate a human origin. A starch-positive $S$. bovis points, on the other hand, very definitely to an animal origin.

\section{REFERENCES}

AbD-el-Malek, Y. \& Gibson, T. (1948). Studies in the bacteriology of milk. I. The streptococci of milk. J. Dairy Res. 15, 233.

Allen, L. A., Pierce, M. A. F. \& Smith, H. M. (1953). Estimation of Streptococcus faecalis, with particular reference to polluted waters. J. Hyg., Camb. 51, 458.

Anderson, J. S., Happold, F. C., McLeod, J. W. \& Thomson, J. G. (1931). On the existence of two forms of diphtheria bacillus, $B$. diphtheriae gravis and $B$. diphtheriae mitis, and a new medium for their differentiation and for the bacteriological diagnosis of diphtheria. J. Path. Bact. 34, 667.

Andrewes, F. W. \& Horder, T. J. (1906). A study of the streptococci pathogenic to man. Lancet, ii, 708.

Ayers, S. H. \& Mudge, C. S. (1923). Streptococei of faeces and mouth of cows. V. Studies of the streptococci. J. infect. Dis. 33, 155.

Ayers, S. H. \& RuPP, P. (1922). Differentiation of haemolytic streptococci from human and bovine sources by the hydrolysis of sodium hippurate. J. infect. Dis. 30, 388. 
Cooper, K. E., BAKer, J. H., Elliot, E. M. L. \& Wood, N. (1942). Isolation of bacteria by tetrathionate broth. J. Path. Bact. 54, 529.

Cooper, K. E. \& Linton, A. H. (1947). The value of thallium acetate for the isolation of gonococci and streptococci. Mon. Bull. Minist. Hlth Lab. Serv. 6, 204.

Cooper, K. E., Mayr-Harting, A. \& Mclachlan, A. E. W. (1950). Laboratory examinations for gonococcal infection in the female. Brit. J. vener. Dis. 26, 16.

Cooper, K. E., Wood, N., Elliot, E., Casweld, M. \& Small, W. (1942). Isolation of Bact. paratyphosum $B$ from faeces. J. Path. Bact. 54, 345.

Dible, J. H. (1921). The enterococcus and the faecal streptococci; their properties and relations. J. Path. Bact. 24, 3.

Fleming, A. (1932). On the specific antibacterial properties of penicillin and potassium tellurite. J. Path. Bact. 35, 831.

HaRoLD, C. H. H. (1936). Rep. metrop. Wat. Bd, 31, 22.

Orla-Jensen, S. (1942). The Lactic Acid Bacteria, 2nd ed. p. 138. Copenhagen: Munksgaard.

Rep. minist Hlth, Lond. (1940). No. 71. Bacteriological examination of Water Supplies.

Shattock, P. M. F. (1949). The streptococci of group D; the serological grouping of Streptococcus bovis and observations on serologically refractory group D strains. J. gen. Microbiol. 3, 80.

Shattock, P. M. F. \& Hirsch, A. (1947). A liquid medium buffered at pH 9.6 for the differentiation of Streptococcus faecalis from S. lactis. J. Path. Bact. 59, 495.

Shatтock, P. M. F. \& Matrick, A. T. R. (1943). The serological grouping of Streptococcus lactis (group N) and its relationship to Streptococcus faecalis. J. Hyg., Camb. 43, 173.

Sharpe, E. M. (1948). Some biochemical characteristics of group D streptococci isolated from infants' faeces with special reference to their tyrosine decarboxylase activity. Proc. Soc. appl. Bact. 11, 13.

Sherman, J. M. (1937). The streptococci. Bact. Rev. 1, 3.

Sherman, J. M. (1938). The enterococci and related streptococci. J. Bact. 35, 81.

\section{Note on the Standardization of the Janus Green Milk Test}

Because the dye Janus Green B (dimethylsafranin azodimethylaniline: a Gurr preparation, batch no. 1041) was manufactured mainly for staining purposes and no actual account was recorded of its impurities or ash content, it was found necessary to standardize fresh batches of the dye against this original preparation. The dye preparations examined were: (1) Janus Green B (Gurr preparation, batch no. 351); (2) Janus Green (British Drug Houses Ltd. preparation, batch no. 183914); (3) Original batch, namely Janus Green B (Gurr preparation batch no. 1041). The depth of the blue colour produced by these dye preparations in sterile milk showed that the B.D.H. batch (no. 183914) and the original Gurr batch (no. 1041) both produced a deep blue colour in final concentrations of $1 / 10,000$; but the other Gurr batch (no. 351) only showed a faint bluish tint in a final concentration reaching 1/5000.

Preparation of Janus Green milk. A $1 \%$ solution was prepared from each dye batch in sterile glass-distilled water, heated in 'a water-bath at $80-100^{\circ}$ for $15 \mathrm{~min}$. and then cooled. Bulk skimmed milk sterilized by steaming, was divided into three separate portions which were treated as follows:

The first portion. From batch 1041 (Gurr), the dye was added to the milk to produce a 1/10,000 concentration, and then distributed in $5 \mathrm{ml}$. amounts in 
screw-capped bottles. This batch formed the original Janus Green B milk to be considered as the basis of standardization.

The second portion. The milk was divided into four parts. From the $1 \%$ solution of the batch no. 183914 (B.D.H.) the dye was added, in different proportions, to bring the final concentrations in these milks to $1 / 12,000$, $1 / 10,000,1 / 8000,1 / 5000$, respectively. The milk and dye was then distributed into screw-capped bottles in $5 \mathrm{ml}$. amounts and labelled.

The third portion was treated as the second portion except that dye batch no. 351 (Gurr) was used instead of the B.D.H. batch.

Test cultures. Sixty cultures of excremental streptococci from the collection isolated by the tellurite method ( 20 human, 20 cow and 20 sheep) were subcultured in Bactopeptone broth and incubated at $37^{\circ}$ for $16 \mathrm{hr}$.

Method. One loop ( $4 \mathrm{~mm}$. diam.) inoculation was made from each of the $16 \mathrm{hr}$. Bactopeptone broth cultures into bottles of Janus Green milk from the three different batches. The milks were then incubated in a water-bath at $37^{\circ}$ with uninoculated controls. Readings were made after $16 \mathrm{hr}$.

Results. The original Janus Green B milk test (containing 1/10,000 Janus Green $B$ batch no. 1041, Gurr) revealed that twenty-eight cultures (16 human, 12 animal) reduced the dye to the quinonoid red or pale pink form within $16 \mathrm{hr}$. at $37^{\circ}$, i.e gave a positive test. In the remaining thirty-two cultures the dye remained oxidized (blue) or was only partially reduced (mauve, violet, dirty red), i.e. gave a negative test.

With the other dye +milk preparations, only the 1/8000 with batch no. 183914 (B.D.H.) milk test reproduced the same results as of the original test.

The 1/10,000 (B.D.H.) milk test, on the other hand, gave nine 'falsepositive' results, while the $1 / 5000$ concentration of the same batch showed an over-poising action in eleven cultures (i.e. false-negative results). Janus Green B (batch no. 351, Gurr) in the various concentrations used in milks, was reduced by all the strains involved in this investigation, either to the pale pink or the leucocolour.

From these results it may be assumed that in order to maintain its differential value between excretal streptococci, the Janus Green milk test should either be prepared in $1 / 10,000$ final concentration from the 'Gurr preparation batch no. 1041' or in 1/8000 final concentration from the 'B.D.H. preparation batch no. 183914'. Every batch should be standardized, and not all are suitable. A small stock of B.D.H. preparation no. 183914 has been reserved to standardize new batches of Janus Green. 